\title{
Short-Term Fuzzy Forecasting of Brent Oil Prices
}

\author{
Ismagilov I. I. ${ }^{1} \&$ Khasanova S. F. ${ }^{1}$ \\ ${ }^{1}$ Institute of Management, Economics and Finance, Kazan Federal University, Kazan, Russia \\ Correspondence: Ismagilov I. I., Institute of Management, Economics and Finance, Kazan Federal University, \\ Kazan, 420008, Russia. E-mail: iiismag@mail.ru; svetlana-khasanova-1@yandex.ru
}

Received: December 27, 2014 Accepted: February 19, 2015 Online Published: April 30, 2015

doi:10.5539/ass.v11n11p60

URL: http://dx.doi.org/10.5539/ass.v11n11p60

\begin{abstract}
Oil prices movements is very important macroeconomic factor for decision making. The accuracy of results for different types of oil brands depends on models and algorithms. This paper evaluates the effectiveness of using fuzzy sets to forecast daily Brent oil prices. It also contains possible modifications of the proposed method and in comparison with basic methods. The results suggest that Brent oil prices series have short memory because using information about last 2-days prices shows better forecast accuracy. Forecasting based on fixed universe of discourse shows better efficiency and it also proves that oil prices series has short memory. Adding the probability of switching between linguistic terms in defuzzification function could be used to improve accuracy of predictions. Also the approach can take into consideration expert's opinion about direction of future variation. The effective expert's work can reduce errors of forecast from $1.5 \%$ till $0.76 \%$. But this modification can be used if experts correctly guess the direction of the change in trend in eight out of ten cases and more. The reasonable obtained results can be used by analysts dealing with the prediction of oil prices.
\end{abstract}

Keywords: petroleum prices, soft computing, Brent, fuzzy logic, time series, fuzzy sets, forecast, prediction, expert's opinion, stock market

\section{Introduction}

Oil is the most important energy resources in the world. Total turnover of oil takes a large share of world trade. Oil prices importantly concern to international organizations, governments, enterprises and different type of investors. Increase in oil prices on 10\% influence on USA' GDP growth on $0,6-2,5 \%$ in research of Suater and Awerbuch (2006). Much has been said and written about influencing factors like weather, stock level, political games and psychological expectations. It has been establish by recent studies that high oil prices directly affect macroeconomic indicators such inflation in Cologni and Manera (2009), Farzanegan and Markwardt (2009), GDP in researches of Cologni and Manera, Doroodian and Boyd (2003), Prasad et al. (Prasad, Narayan, \& Narayan, 2007), investments in researches of Abel (1990), Hamilton (2003), Rafiq et al. (Rafiq \& Mallick, 2008) and generating financial crisis that confirmed in researches of Gisser and Goodwin (1986), Jones et al. (Jones, Leiby, \& PAIK, 2004). These dependences have nonlinear and even chaotic character so that forecasting oil prices is difficult and always actual problem.

Contingently forecasting of oil prices can be divides into three types: short-term (1-3 days), middle-term (up to one year) and long-term forecasting (more than one year). Long-term forecasting usually bases on traditional econometric techniques such regression models that considering different factors as geopolitics, scientific and technical process, level of world oil reserves, social environment and other factors impacted on oil prices. Short-term and middle-term forecasting uses nonlinear and nonstationary time series models.

Carry out some overview about most popular techniques on short-term forecasting oil prices. Sadorsky (1999) uses several different univariate and multivariate statistical models to forecast oil volatility and show that forecast accuracy not associated with complexity of model. Models like state space, vector autoregression and bivariate GARCH do not perform as well as the single equation GARCH model.

Alexandra Costello et al. (Costello, Asem, \& Gardner, 2008) compare the ARMA with historical simulation to the semi-parametric GARCH model. The results suggest that the semi-parametric GARCH model generates VaR forecasts that are superior to the VaR forecasts from the ARMA with historical simulation. This is due to the fact that GARCH captures volatility clustering. Weakness in GARCH model is based on using the normal 
assumption on the future risk dispersion. Marimoutou et al. propose Extreme Value Theory for forecasting VaR of Brent and WTI oil prices. Proposed method and GARCH $(1,1)$-t model may provide equally good results.

In paper Cheong (2009) a flexible autoregressive conditional heteroskedasticity (ARCH) model is used to take into account the stylized volatility facts such as clustering volatility, asymmetric news impact and long memory volatility among others. Brent series, the specification of conditional variance gains additional accuracy over the conditional standard-deviation in the time-varying volatility modeling. The Brent series encounters the leverage effect on crude oil price shocks. This implies that the downward movements (shocks) in the Brent crude oil market are follow by greater volatilities than upward movements of the same magnitude. For WTI series, there is no asymmetric effect of so-called 'bad' or 'good' news to on the WTI crude oil market. These results contrast with those of the leverage effect in the Brent market. Despite the research of Lanza et al. (Lanza, Manera, \& Mcaleer, 2006) showed the dynamic volatilities in the returns in the WTI oil forward and future prices could be either independent or interdependent over time.

Kang et al. investigate efficacy of forecasting oil prices on three global oil markets (WTI, Brent, Dubai) using ARFIMA-GARCH type models: ARIMA-GARCH, ARFIMA-GARCH, ARFIMA-IGARCH и ARFIMA-FIGARCH. PP (Phillips-Peron) and KPSS (Kwiatkowski, Phillips, Schmidt, and Shin) tests show the return series are stationary. The CGARCH and FIGARCH models are better equipped to capture persistence than are the GARCH and IGARCH models. More importantly, the FIGARCH model for the Brent and Dubai crude oils provides superior performance in out-of-sample volatility forecasts, whereas the CGARCH model for WTI crude oil evidences better forecasting accuracy than do other models. But Mohammadi (2010) suggest that MA(1)-EGARCH and MA(1)-APARCH models get better results for weekly volatility forecasts.

Wei et al. expand researches of ARFIMA-GARCH type models using wide range of linear and nonlinear GARCH-type model and more loss functions. No model can outperform all of the other models for either the Brent or the WTI market across different loss functions. However, in general, the nonlinear GARCH-class models, which are capable of capturing long-memory and/or asymmetric volatility, exhibit greater forecasting accuracy than the linear ones, especially in volatility forecasting over longer time horizons, such as five or twenty days. Tabak and Cajueiro (2007) consider that GARCH-type models have better accuracy on long-term volatility forecasts. These results are confirmed by research Yugong Wang et al. Further studies show effectiveness GARCH-type model on forecasting volatility in different oil markets and type of futures, forwards and swops.

Ghaffari and Zare (2009) develop a method based on soft computing approaches to predict the daily variation of the WTI. The predicted daily oil price variation is compared with the actual daily variation of the oil price and the difference is implemented to activate the learning algorithms. The accuracy and reliability of the algorithm estimated how often the predicted variation of the oil price has the same sign as the actual variation and it is $66 \%$.

John Wei-Shan $\mathrm{Hu}$ et al. (2012) demonstrate the recurrent fuzzy neural network model outperformed the multilayer perceptron and the Elman recurrent neural network in forecasting crude oil futures prices and the predictive power improves when increasing the training time. Azadeh et al. (2012) use a flexible neural network-fuzzy mathematical programming algorithm on long-term forecasting. They concluded that the artificial neural network models considerably outperform the fuzzy regression models in terms of mean absolute percentage error (MAPE).

Short-term oil prices and volatilities forecasting is the wildly researched field. GARCH type model show better accuracy for predicting volatility of several types of oil prices and futures. At the same time this models more effective on long-term predictions. Each oil market prices need individual selection of models type and parameters. Other approaches like neural networks, fuzzy computing poorly represented in researches despite the expediency of their application for forecasting of oil prices.

The review show that elements of fuzzy set theory are used in models of forecasting oil prices like the fuzzy regression models and fuzzy neural networks. This paper present a method based on fuzzy logic approach for predicting of oil prices. The proposed method is used to forecast the Brent crude oil spot prices. The rest of paper is organized as follows: Section 2 describes necessary mathematical background and our forecasting methodology. We show modifications and efficiency of our results. Some concluding remarks are drawn in Section 3. 


\section{Materials and Methods}

\subsection{Fuzzy Logic Approach}

The purpose of this work is assessing possibility and efficiency of fuzzy set method for predicting oil prices on Brent oil market. We used the retrospective analysis for estimating forecasts accuracy. This method is the modification of basic approach of Song and Chissom (1993a; 1993b; 1994), Shah and Degtiarev (2004), Mamedova and Dzhabrailova (2014) by using unfixed universe of discourse. The method has several steps.

Step 1: We use day to day differences of the Brent oil prices for the universe of discourse. The linguistic variable is named "Difference of prices".

Step 2: Define the unfixed universe of discourse for each forecasting day as the interval between the minimum and maximum differences of the oil prices for a certain period of time.

Step3: Partition of the unfixed discourse into several and equal length intervals, the number of intervals $(n)$ is equal to number of linguistic terms. Midpoints of these intervals are quantitative values of linguistic terms.

Step 4: Fuzzification of the differences of prices is realized using the formula for each linguistic terms.

$$
m_{A_{j}}\left(u_{j}\right)=\frac{1}{1+C\left(U_{t}-u^{j}\right)^{2}}
$$

where $m_{A_{j}}\left(u_{j}\right)$ is membership function, $U_{t}$ is the actual value of the last difference of prices on day $t, u^{j}$ are the midpoints of intervals, $C$ is the constant which is chosen so to ensure fuzzy data belong into interval [0;1].

The reason for fuzzifying the historical data into fuzzified data is to translate crisp values into fuzzy sets to get a fuzzy series.

Step 5: Selecting the parameter $l>1$ which sets the number of days that will be used to prediction. This parameter estimates the length of memory of time series. Using formula the relationship matrix $\left[R_{t}\right]$ is calculated:

$$
\left[R_{t}\right]=\left[O_{t}\right] \cap\left[K_{t}\right]=\left[\begin{array}{ccc}
R_{11} & \cdots & R_{1 j} \\
\vdots & \ddots & \vdots \\
R_{i 1} & \cdots & R_{i j}
\end{array}\right]
$$

where $\cap$ is the symbol of operation "minimum", $\left[O_{t}\right]$ is the matrix sized $l \times j$ of fuzzy data that preceding the forecast time, $\left[K_{t}\right]$ is the matrix-criterion sized $l \times j$ that contains fuzzy data of forecast time.

Define fuzzy forecast $\left[F_{t}\right]$ as matrix of fuzzy sets:

$$
\left[F_{t}\right]=\left[m_{t+1}\left(u^{1}\right) \ldots m_{t+1}\left(u^{j}\right)\right]=\left[\operatorname{Max}\left(R_{11}, R_{21}, \ldots, R_{i 1}\right) ; \ldots ; \operatorname{Max}\left(R_{1 j}, R_{2 j}, \ldots, R_{i j}\right)\right]
$$

Step 6: Defuzzify the fuzzy data using center of gravity method.

$$
V_{t+1}=\frac{\sum_{j=1}^{n} m_{t+1}\left(u_{j}\right) * u^{j}}{\sum_{j=1}^{n} m_{t+1}\left(u_{j}\right)}
$$

where $V_{t+1}$ is the forecast of the difference of oil price for day $t+1, m_{t+1}\left(u_{j}\right)$ are the fuzzy forecast, $u^{j}$ are the midpoints of intervals, $n$ is the number of linguistic terms.

This crisp value is the forecast of difference of oil prices. Predict price for the next day:

$$
P_{t+1}=A_{t}+V_{t+1}
$$

where $P_{t+1}$ is the forecast the oil price on dayt $+1, A_{t}$ is actual oil price on dayt, $V_{t+1}$ is the forecast of the difference of oil price for day $t+1$.

Step 7: We use the average forecasting error rate (AFER) and mean average error (MAE) to assess effectiveness of the forecasting results:

$$
A F E R=\frac{\sum_{t=1}^{m}\left(\frac{\left|A_{t+1}-P_{t+1}\right|}{A_{t+1}}{ }_{* 100 \%)}\right.}{m}, \quad M A E=\frac{\sum_{t=1}^{m}\left|A_{t+1}-P_{t+1}\right|}{m}
$$

where $A_{t+1}$ denotes the actual oil price and $P_{t+1}$ denotes the forecasting oil price of day $t+1$, respectively. 


\subsection{Selection of Parameters}

Analysis is based on the statistical data of 2680 Brent oil prices quotations during the period from 01 January 2005 till 30 October 2014. The proposed method requires sequential selection of the model parameters for the review period:

1) Number of linguistic terms;

2) $\mathrm{C}$ - constant value;

3) The length of unfixed universe of discourse - the length of period of time that used for defining unfixed universe of discourse;

4) Parameter $l$ - the length of memory that used for generating forecast.

We used nine linguistic terms as the most optimal number. Rational value of constant $\mathrm{C}$ is determined on a discrete grid. Results of selection are shown in Table 1.

Table 1. The results of $\mathrm{C}$ selection (on fixed universe of discourse; $l=2$ ).

\begin{tabular}{ccccccc}
\hline $\mathrm{C}$ & $1 E-10$ & $1 E-09$ & $1 E-08$ & $1 E-07$ & $1 E-06$ & $1 E-05$ \\
$\mathrm{MAE} \$$ & 1.170 & 1.170 & 1.170 & 1.170 & 1.170 & 1.170 \\
$\mathrm{C}$ & $1 E-04$ & 0.001 & 0.01 & 0.1 & 1 & 10 \\
$\mathrm{MAE} \$$ & 1.169 & 1.164 & 1.204 & 1.308 & 1.346 & 1.3528 \\
$\mathrm{C}$ & 100 & 1000 & $1 E 04$ & $1 E 05$ & $1 E 06$ & $1 E 07$ \\
$\mathrm{MAE} \$$ & 1.354 & 1.354 & 1.354 & 1.354 & 1.354 & 1.354 \\
\hline
\end{tabular}

According to the results value $\mathrm{C}$ is appropriate to choose at 0.001 . Studies have been conducted on the selection of the length for the unfixed universe of discourse. Results are shown in Table 2.

Table 2. The results of the selection of the length for unfixed universe of discourse (on $C=0.001 ; l=2$ )

\begin{tabular}{cccccc}
\hline $\mathrm{j}$ & 2 & 3 & 4 & 5 & 6 \\
MAE $\$$ & 1.407 & 1.354 & 1.316 & 1.307 & 1.284 \\
$\mathrm{j}$ & 7 & 8 & 9 & 10 & 11 \\
MAE $\$$ & 1.280 & 1.280 & 1.270 & 1.267 & 1.263 \\
$\mathrm{j}$ & 12 & 13 & 14 & 15 & 16 \\
MAE $\$$ & 1.268 & 1.260 & 1.260 & 1.259 & 1.251 \\
\hline
\end{tabular}

From Table 2, we can see that using unfixed universe of discourse for forecast gives the lower accuracy than fixed universe of discourse that doesn't change for each of days. Using unfixed universe of discourse gains the minimum error equal $\$ 1.2505$; using fixed universe of discourse reaches error equal $\$ 1.16422$. But the unfixed universe of discourse can show better accuracy on another time series.

Table 3. The results of $l$ selection (on fixed universe of discourse, $\mathrm{C}=0.001$ )

\begin{tabular}{ccccc}
\hline 1 & 2 & 3 & 4 & 5 \\
MAE $\$$ & 1.164 & 1.165 & 1.165 & 1.165 \\
1 & 6 & 10 & 15 & 20 \\
MAE $\$$ & 1.165 & 1.165 & 1.165 & 1.166 \\
\hline
\end{tabular}

Expedient to use the shortest length of the prehistory $l=2$ days, as this increases the accuracy of prediction as compared with other values. This means that time series of Brent oil prices have a short memory. The future oil price is determined by the current price only. 


\subsection{Modifications of Method: Using Expert's Opinion}

As a modification of the method we provide the use of expert opinions about the direction of change in oil prices. For this purposes forecasting is carried out in three variants: the decline, permanency and increase of oil prices. Expert chooses one of these variants and the model gives the forecast of it. All the linguistic terms are divided into three equal groups. The first third of linguistic terms is used for the variant "decline" in Step 6 (in our casej $\in[1 ; 3]$ ). The last third of linguistic terms is used for the expectation "increase" (in our casej $\in[7 ; 9]$ ). Remaining linguistic terms are used if expert opinion is "permanency" (in our case $j \in[4 ; 6]$ ). This "soft" forecasting shows better results, because model can use experience and knowledge of expert, the results shown in Table 4.

Table 4. Comparison of basic method and "soft" method (on unfixed universe of disclosure in 10 days, $\mathrm{C}=0.01, \mathrm{l}=2$ )

\begin{tabular}{ccc}
\hline Index & Basic method & "Soft" method \\
\hline Maximum MAE (AFER) & 10.35 & 9.39 \\
MAE & $(16.84 \%)$ & $(10.08 \%)$ \\
(AFER) & 1.1642 & 0.6053 \\
\end{tabular}

Selection of parameters for "Soft" method shows the best efficiency when we use unfixed universe of discourse.

The proposed method of forecasting provides a sufficiently accuracy. If expert always chooses the right variant of future oil fluctuation, the smallest middle absolute error (MAE) and average forecasting error rate (AFER) can be reached to 60 cents or $0.76 \%$. Forecasting without expert opinion has MAE $\$ 1.16$ or AFER $1.5 \%$. A comparison between these methods is shown in Figure 1.

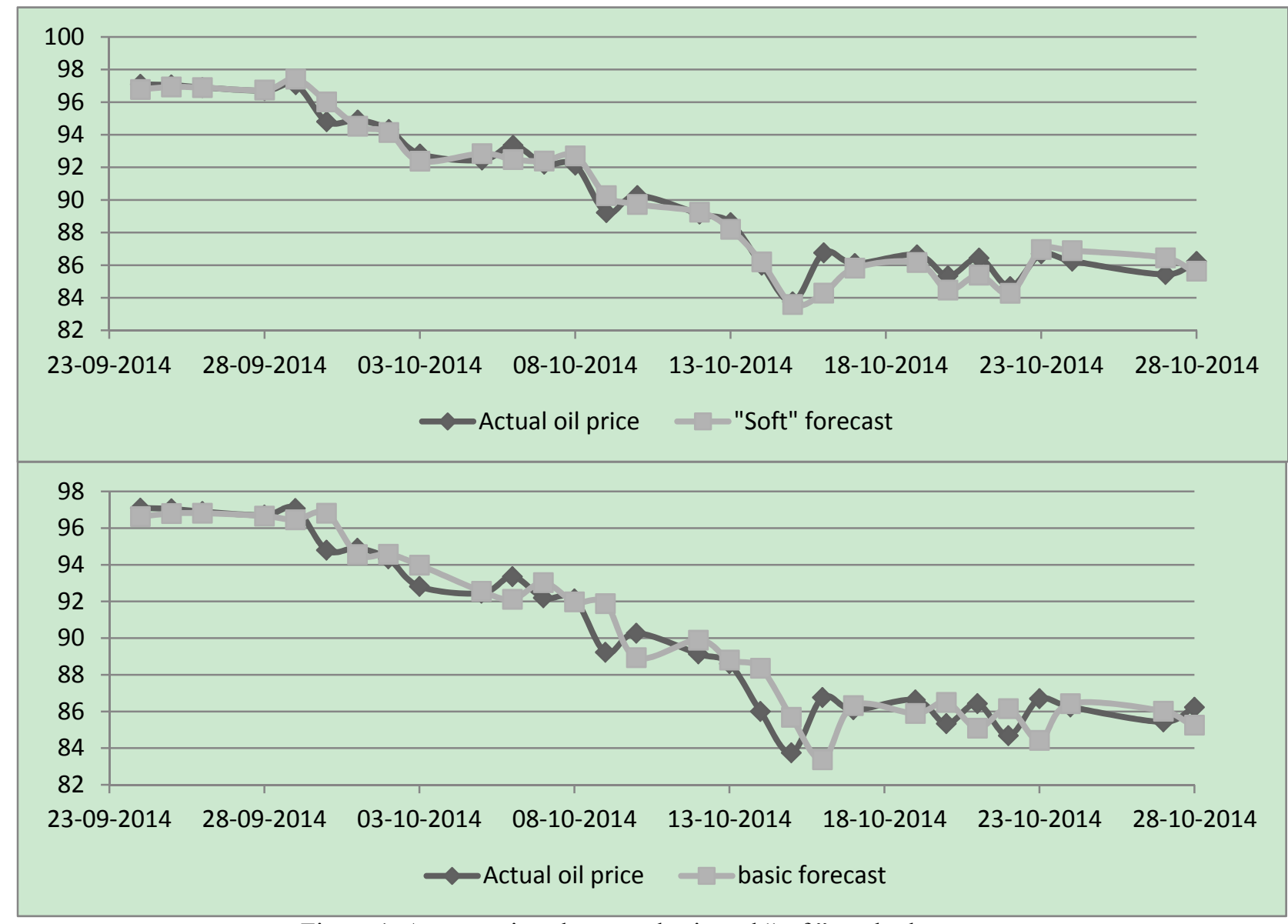

Figure 1. A comparison between basic and "soft" methods 
Expert's efficiency in predicting direction in fluctuation of future oil price affects on forecast accuracy. Researches show that "soft" method should be used when expert chooses the right direction in $80 \%$ of cases. Otherwise the basic method has better results.

\subsection{Modifications of Method: Consideration of Probability}

Define for each day linguistic term with the highest membership function. Calculate the probability of switching from current linguistic term to other term from specific time. Basic and "soft" methods are modified by adding probabilities in defuzzification's function.

$$
V_{t+1}=\frac{\sum_{j=1}^{n} m_{t+1}\left(u_{j}\right) * u^{j} * P_{t}^{j}}{\sum_{j=1}^{n} m_{t+1}\left(u_{j}\right)}
$$

where $P_{t}^{j}$ is probability to switch from previous linguistic term to linguistic term $j$.

Amount of days that used to probability calculation affect on forecast accuracy. The results are showed in Table 5 .

Table 5. Comparison between amounts of days that used to probability calculation on fixed and unfixed universe of discourse

\begin{tabular}{ccccc}
\hline \multirow{2}{*}{ Amount of days that used to probability calculation } & \multicolumn{3}{c}{ On fixed universe of discourse } \\
\cline { 2 - 5 } & \multicolumn{2}{c}{ Basic method } & "Soft" method \\
\cline { 2 - 5 } & MAE & MAPE & MAE & MAPE \\
\hline 3 & 1.169 & 1.47 & 0.9869 & 1.24 \\
14 & 1.1498 & 1.44 & 1.0151 & 1.2824 \\
21 & 1.1426 & 1.439 & 1.03 & 1.29 \\
30 & 1.1427 & 1.4393 & 1.0407 & 1.3126 \\
Accumulative from 1 January 2005 & 1.1388 & 1.43 & 1.0467 & 1.32 \\
Excluding probabilities & 1.1395 & 1.4363 & 1.0874 & 1.3724 \\
Naive forecast & 1.204 & 1.5279 & 1.0814 & 1.3831 \\
\hline
\end{tabular}

\begin{tabular}{ccccc}
\hline \multirow{2}{*}{ Amount of days that used to probability calculation } & \multicolumn{3}{c}{ On unfixed universe of discourse } \\
\cline { 2 - 5 } & \multicolumn{2}{c}{ Basic method } & \multicolumn{2}{c}{ "Soft" method } \\
\cline { 2 - 5 } & MAE & MAPE & MAE & MAPE \\
\hline 7 & 1.1937 & 1.5008 & 0.8471 & 1.0736 \\
14 & 1.1678 & 1.4715 & 0.913 & 1.15 \\
21 & 1.1621 & 1.466 & 0.9607 & 1.2131 \\
Accumulative from 1 January 2005 & 1.1394 & 1.4375 & 1.0049 & 1.2679 \\
Excluding probabilities & 1.2999 & 1.6168 & 0.602 & 0.754 \\
Naive forecast & 1.1277 & 1.4349 & & \\
\hline
\end{tabular}

The forecast accuracy of basic method is improved from error $\$ 1.1642$ to $\$ 1.1394$. But this approach reduces effectiveness of "soft" method that uses expert's opinion, meaning it does not need additional information.

\section{Conclusions}

Last investigations have detected that oil prices can be stationary process for one period of time and nonstationary on another one. Most of these researches suggest that oil prices time series' memory contain internal information about economic, political, social, natural and psychological impact factors. And generalized 
autoregressive conditional heteroskedastic $(\mathrm{GARCH})$ models and their variants tend to work better than other techniques for volatility prediction. In contrast, there has been relatively little work done on modeling other techniques such neural networks, fuzzy sets, EMD etc, which show good results for several time series.

This paper uses the fuzzy sets approach for short-term forecasting of Brent oil prices. The results suggest that Brent oil prices series have short memory because using information about last 2-days prices shows better forecast accuracy. Forecasting based on fixed universe of discourse shows better efficiency and it also proves that oil prices series has short memory.

Adding the probability of switching between linguistic terms in defuzzification function could be used to improve accuracy of predictions. Also the approach can take into consideration expert's opinion about direction of future variation. The effective expert's work can reduce errors of forecast from $1.5 \%$ till $0.76 \%$. But this modification can be used if experts correctly guess the direction of the change in trend in eight out of ten cases and more.

The forecasting technique is differed by sufficient simplicity. Efficiency outperforms other models. The using of expert systems demonstrates high accuracy of the forecasts. These results are useful for those who need in forecasts of petroleum prices.

\section{References}

Abel, A. B. (1990). Chapter 14 Consumption and investment. Handbook of Monetary Economics, 2(C), 725-778. http://dx.doi.org/10.1016/S1573-4498(05)80021-9

Ankudinov, B., \& Lebedev, O. V. (2014). Job insecurity and employees' motivation to engage in professional education. American Journal of Applied Sciences, 11(5), 860-865. http://dx.doi.org/10.3844/ajassp. 2014.860 .865

Awerbuch, S., \& Sauter, R. (2006). Exploiting the oil-GDP effect to support renewables deployment. Energy Policy, 34(17), 2805-2819. http://dx.doi.org/10.1016/j.enpol.2005.04.020

Azadeh, A., Moghaddam, M., Khakzad, M., \& Ebrahimipour, V. (2012). A flexible neural network-fuzzy mathematical programming algorithm for improvement of oil price estimation and forecasting. Computers and Industrial Engineering, 62(2), 421-430. http://dx.doi.org/10.1016/j.cie.2011.06.019

Chen, S. (1996). Forecasting enrollments based on fuzzy time series. Fuzzy Sets and Systems, 81(3), 311-319. http://dx.doi.org/10.1016/0165-0114(95)00220-0

Cheong, C. W. (2009). Modeling and forecasting crude oil markets using ARCH-type models. Energy Policy, 37(6), 2346-2355. http://dx.doi.org/10.1016/j.enpol.2009.02.026

Cologni, A., \& Manera, M. (2009). The asymmetric effects of oil shocks on output growth: A Markov-Switching analysis for the G-7 countries. Economic Modelling, 26(1), 1-29. http://dx.doi.org/10.1016/j.econmod. 2008.05.006

Costello, A., Asem, E., \& Gardner, E. (2008). Comparison of historically simulated VaR: Evidence from oil prices. Energy Economics, 30(5), 2154-2166. http://dx.doi.org/10.1016/j.eneco.2008.01.011

Doroodian, K., \& Boyd, R. (2003). The linkage between oil price shocks and economic growth with inflation in the presence of technological advances: A CGE model. Energy Policy, 31(10), 989-1006. http://dx.doi.org/10.1016/S0301-4215(02)00141-6

Farzanegan, M. R., \& Markwardt, G. (2009). The effects of oil price shocks on the Iranian economy. Energy Economics, 31(1), 134-151. http://dx.doi.org/10.1016/j.eneco.2008.09.003

Ghaffari, A., \& Zare, S. (2009). A novel algorithm for prediction of crude oil price variation based on soft computing. Energy Economics, 31(4), 531-536. http://dx.doi.org/10.1016/j.eneco.2009.01.006

Gisser, M., \& Goodwin, T. H. (1986). Crude Oil and the Macroeconomy: Tests of Some Popular Notions: Note Journal of Money, Credit and Banking, 18(1), 95-103. http://dx.doi.org/10.2307/1992323

Hamilton, J. D. (2003). What is an oil shock? Journal of Econometrics, 113(2), 363-398. http://dx.doi.org/10.1016/S0304-4076(02)00207-5

Hu, J. W., Hu, Y., \& Lin, R. R. (2012). Applying neural networks to prices prediction of crude oil futures. Mathematical Problems in Engineering. http://dx.doi.org/10.1155/2012/959040

Ismagilov, I. I. (2006). An approach to ordering of systems of the Walsh discrete functions. Radioelectronics and Communications Systems, 49(1), 46-50. 
Ismagilov, I. I. (2010). Oblique generalizations of the Walsh basis. Radioelectronics and Communications Systems, 53(12), 625-635. http://dx.doi.org/10.3103/S0735272710120010

Jilani, T. A., Burney, S. M. A., \& Ardil, C. (2007). Fuzzy metric approach for fuzzy time series forecasting based on frequency density based partitioning. Proceedings of World Academy of Science, Engineering and Technology, 23, 333-338. Retrieved from http://www.scopus.com/inward/record.url?eid=2-s2.040249108253\&partnerID $=40 \& m d 5=284 f 5 f 3323758 \mathrm{e} 1234 \mathrm{c} 5 \mathrm{f} 94 \mathrm{~b} 52 \mathrm{a} 0 \mathrm{ca} 45$

Jones, D. W., Leiby, P. N., \& PAIK, I. K. (2004). Oil price shocks and the macroeconomy: What has been learned since 1996. Energy Journal, 25(2), 1-32. http://dx.doi.org/10.5547/ISSN0195-6574-EJVol25-No2-1

Lanza, A., Manera, M., \& Mcaleer, M. (2006). Modeling dynamic conditional correlations in WTI oil forward and futures returns. Finance Research Letters, 3(2), 114-132. http://dx.doi.org/10.1016/j.frl.2006.01.005

Mamedova, M. G., \& Dzhabrailova, Z. G. (2004). Application of fuzzy logic in the demographic forecast. Information Technology, 3. Retrieved from http://www.informika.ru/windows/magaz/it/2004/03/ inftech.html \# 8

Mohammadi, H., \& SU, L. (2010). International evidence on crude oil price dynamics: Applications of ARIMA-GARCH models. Energy Economics, 32(5), 1001-1008. http://dx.doi.org/10.1016/j.eneco.2010.04. 009

Prasad, A., Narayan, P. K., \& Narayan, J. (2007). Exploring the oil price and real GDP nexus for a small island economy, the Fiji Islands. Energy Policy, 35(12), 6506-6513. http://dx.doi.org/10.1016/j.enpol.2007.07.032

Rafiq, M. S., \& Mallick, S. K. (2008). The effect of monetary policy on output in EMU3. A sign restriction approach. Journal of Macroeconomics, 30(4), 1756-1791. http://dx.doi.org/10.1016/j.jmacro.2007.12.003

Sadorsky, P. (1999). Oil price shocks and stock market activity. Energy Economics, 21(5), 449-469. http://dx.doi.org/10.1016/S0140-9883(99)00020-1

Shah, M., \& Degtiarev, K. Y. (2004). Forecasting Enrollment Model Based on First-Order Fuzzy Time Series. Proc. Int.Conf. Computational Intelligence (ICCI) (pp. 375-378).

Song, Q., \& Chissom, B. S. (1993). Forecasting enrollments with fuzzy time series - Part I. Fuzzy Sets and Systems, 54(1), 1-9. http://dx.doi.org/10.1016/0165-0114(93)90355-L

Song, Q., \& Chissom, B. S. (1993). Fuzzy time series and its models. Fuzzy Sets and Systems, 54(3), 269-277. http://dx.doi.org/10.1016/0165-0114(93)90372-O

Song, Q., \& Chissom, B. S. (1994). Forecasting enrollments with fuzzy time series - part II. Fuzzy Sets and Systems, 62(1), 1-8. http://dx.doi.org/10.1016/0165-0114(94)90067-1

Tabak, B. M., \& Cajueiro, D. O. (2007). Are the crude oil markets becoming weakly efficient over time? A test for time-varying long-range dependence in prices and volatility. Energy Economics, 29(1), 28-36. http://dx.doi.org/10.1016/j.eneco.2006.06.007

Tanuwijaya, K., \& Chen, S. (2009). A new method to forecast enrollments using fuzzy time series and clustering techniques. Proceedings of the 2009 International Conference on Machine Learning and Cybernetics 2009, 3026-3029. Retrieved from http://www.scopus.com/inward/record.url?eid=2-s2.0-70350719486\& partnerID $=40 \&$ md5 $=$ cafed8234ac8073337cf1695ef41 cb57

Yarushkina, N. G., Afanasiev, T. V., \& Perfil'eva, I. G. (2010). Intelligent analysis of time series: a tutorial. Ulyanovsk. UISTU. Retrieved from http://icit12.sstu.ru/ocs/index.php/icit/icit12

\section{Copyrights}

Copyright for this article is retained by the author(s), with first publication rights granted to the journal.

This is an open-access article distributed under the terms and conditions of the Creative Commons Attribution license (http://creativecommons.org/licenses/by/3.0/). 